\title{
Influence of ethanol-wet dentin, adhesive mode of application, and aging on bond strength of universal adhesive
}

\section{Mauricio Yugo de SOUZA(a) Rebeca DI NICOLÓ(b) Eduardo BRESCIANI(a)}

(a) Universidade Estadual Paulista - Unesp, Institute of Science and Technology, Department of Restorative Dentistry, São José dos Campos, SP, Brazil.

(b) Universidade Estadual Paulista - Unesp, Institute of Science and Technology, Department of Social Dentistry and Pediatric Clinics, São José dos Campos, SP, Brazil.
Declaration of Interests: The authors certify that they have no commercial or associative interest that represents a conflict of interest in connection with the manuscript.

\section{Corresponding Author:}

Eduardo Bresciani

E-mail: eduardo.bresciani@unesp.br

https://doi.org/10.1590/1807-3107bor-2018.vol32.0102

Submitted: April 12, 2018

Accepted for publication: August 01, 2018

Last revision:August 23, 2018

\begin{abstract}
The aim of this study was to evaluate the effect of ethanol on the bond longevity of a universal adhesive system to bovine dentin, under different modes of adhesive application and artificial aging. Bovine dentin was exposed, and the smear layer was standardized by sandpaper polishing. Specimens were randomly divided into 2 groups: ethanol (E) and non-ethanol (N). Groups were subdivided according to adhesive mode of application into etch-and-rinse (Er) and self-etching (S). Resin blocks were built onto the treated surface, and the specimens were stored in deionized water at $37^{\circ} \mathrm{C}$ for $48 \mathrm{~h}$. Half of the specimens $(n=10)$ were subjected to thermomechanical aging (A for aged and Na for non-aged). Resin/dentin beams were obtained and subjected to microtensile test in a universal testing machine. Data were analyzed using a three-way ANOVA and Tukey's tests $(\alpha=5 \%)$. There was interaction among the three factors $(p=0.0003)$. The use of ethanol resulted in higher values, except for the Er and $\mathrm{Na}$ groups (E_Er_Na = N_Er_Na). The mode of application was similar, except for the N and A groups (N_S_A > N_Er_A). For the A groups, the values were lower, except in the cases using ethanol, in which the results were not affected. The study concluded that the use of ethanol resulted in higher microtensile bond strength values, even after aging. The mode of adhesive application did not influence the results.
\end{abstract}

Keywords: Aging; Dental Bonding; Dentin; Ethanol.

\section{Introduction}

The improvement of restorative techniques that focus on dental substrate preservation is possible due to the constant evolution of and research on dental adhesives and its effects on dental substrates. ${ }^{1}$ Dental tissues present different responses to acid-etching procedures. While enamel adhesion is facilitated due to a greater quantity of hydroxyapatite crystals and consequent adequate formation of resin tags, the dentin has a great amount of organic components, mainly collagen fibers, extension of odontoblasts, and dentinal fluid, which lead to a more sensitive procedure. ${ }^{2}$ Dentin adhesion is still a challenge in adhesive dentistry.

The popularity of self-etching adhesive systems has increased due to their user-friendly characteristics, mainly as a result of fewer clinical steps and adequate bonding. ${ }^{3}$ Such adhesives promote simultaneous 
demineralization and resin infiltration, leading to a lower risk of failure in adhesive penetration. Acidic monomers are gradually buffered with increasing dentin depth by the mineral content of the substrate. Self-etching adhesion reduces possible problems observed in the total-etching technique; it promotes better sealing, which might result in less postoperative sensitivity, and forms a more homogeneous hybrid layer, which may consequently influence the longevity of the restoration. ${ }^{4}$ Universal adhesives can be used in self-etch, total-etch, or selective modes; in enamel, pre-etching the surface is recommended to increase the bond strength, whereas in dentin, the universal adhesive system can be applied directly. 5,6

Regardless of the adhesive application method, the presence of water is important to allow the penetration of hydrophilic resin monomers within the collagen fibrils, to allow the formation of the hybrid layer and promote bonding. Some universal adhesive systems, besides the acidic monomer components, present 10-methacryloyloxydecyl dihydrogen phosphate (10-MDP), which is capable of chemically bonding to dentin by calcium chelation, leading to a more stable adhesion to dental substrates. ${ }^{2,7}$

The presence of water in the dentin layer is required to form a stable hybrid layer. On the other hand, water is also responsible for the long-term hydrolysis of the bonded interface. ${ }^{4}$ In an attempt to eliminate or reduce the inconvenient long-term effects of water, the ethanol wet bonding technique (EWBT) in association to hydrophobic adhesive systems has been proposed. ${ }^{8}$ Ethanol is an efficient solvent ${ }^{9}$ with less hydrogen-bonding capacity. It causes the chemical dehydration of the collagen network, leading to a relatively hydrophobic collagen matrix. Ethanol hinders the hydrolysis of the bonding interface and allows the proper infiltration of resin monomers for the formation of the hybrid layer. ${ }^{10,11}$

In the simplified technique, $100 \%$ ethanol is applied for $60 \mathrm{~s}$, which is a clinically acceptable procedure time. ${ }^{12}$ The in vitro hybrid layer formed using the EWBT is less hydrophilic and has less amount of water on the surface. It is also more resistant to the hydrolytic degradation caused by metalloproteinases (MMPs). ${ }^{10}$ Once collagen fibrils are effectively protected, this characteristic provides greater longevity to the adhesive interface, leading to more stable bonding. ${ }^{12}$ On the other hand, due to the high volatility of ethanol, the EWBT is very sensitive and does not completely displace water. ${ }^{13}$

The remaining water after ethanol application might interfere with adhesive procedures if a single hydrophobic adhesive is used, supporting the possible use of hydrophilic systems as well. ${ }^{14}$ There are no studies reporting the use of the EWBT with hydrophilic adhesive systems. Therefore, this study aimed to evaluate the influence of ethanol, the mode of adhesive application, and aging on the bond strength of a universal adhesive to bovine dentin.

This study evaluated the following alternative and null hypotheses. H1: The use of the ethanol technique positively influences bond strength. $\mathrm{H}_{0} 2$ : The mode of application of the adhesive system does not influence bond strength. $\mathrm{H}_{\mathrm{o}} 3$ : Thermomechanical cycling (aging) does not result in a significant effect on bond strength. $\mathrm{H}_{0} 4$ : There is no interaction between all factors.

\section{Methodology}

Eighty healthy bovine teeth were used. Their roots were cut close to the cementum-enamel junction, and the buccal surface was grounded using 600-grit sandpaper (SiC, Fepa-P), resulting in a minimum dentin area of $6 \times 6 \mathrm{~mm} \cdot{ }^{15}$ The specimens were embedded in self-curing acrylic resin (Jet Classic, São Paulo, SP, Brazil) with the dentin surface facing down. The smear layer was standardized using an automated polishing device (Autopol, Panambra, São Paulo, SP, Brazil) with 600-grit sandpaper (SiC Fepa-P) under constant water irrigation at $300 \mathrm{rpm}$ for $30 \mathrm{~s}$, in accordance with ISO / TS11405:2015.

The specimens were randomly divided into ethanol $(E)$ and non-ethanol $(N)$ groups $(n=40)$. For the E group, 100\% ethanol was actively applied on the dentin surface with a microbrush for $60 \mathrm{~s}^{13}$ followed by light air-blasting to remove excess of water from the surface and keep it moist. Specimens were further subdivided into etch-and-rinse (Er) or self-etching (S), according to the adhesive application mode. As a result, the $\mathrm{E}$ and $\mathrm{N}$ groups were further distributed into the following divisions: E_Er, E_S, 
N_Er, and N_S. The adhesive system (Single Bond Universal - 3M Deutschland GmbH, Neuss, Germany) was actively applied for $20 \mathrm{~s}$, in accordance to the manufacturer's specifications. For the Er group, 37\% phosphoric acid (37\% Condac - FGM, Santa Catarina, SC, Brazil) was applied for $20 \mathrm{~s}$ prior to the application of $100 \%$ ethanol. The adhesive system was lightactivated for $20 \mathrm{~s}$ with a LED device (Radii-Cal - SDI, Victoria, Australia), with irradiance at $900 \mathrm{~mW} / \mathrm{cm}^{2}$. The universal adhesive components used in this study include bisphenol-A-glycidyl methacrylate (Bis-GMA), 2-hydroxyethyl methacrylate (HEMA), 10-MDP, decamethylene dimethacrylate, ethyl methacryalate, propenoic acid, a copolymer of acrylic and itaconic acid, dimethylaminobenzoate, methyl ethyl ketone, ethanol, water, camphorquinone, and silane-treated silica.

A resin block (Filtek Z350 XT, shade A2E, 3M ESPE) was built onto the treated surface using a silicon mold in two 2-mm increments, light-cured for $20 \mathrm{~s}$ each. The specimens were stored in deionized water at $37^{\circ} \mathrm{C}$ for $48 \mathrm{~h}$ to allow adequate post-curing time of the restoration and to minimize the loss of samples due to the pretest. ${ }^{16}$

Half of the specimens were not aged $(\mathrm{Na})$, while the other half were submitted to aging (A) prior to microtensile bond testing. Acronyms for the resulting groups are as follows: E_Er_Na, E_S_Na, N_Er_Na, and N_S_Na, for Na groups; and E_Er_A, E_S_A, N_Er_A, and N_S_A for A groups.

\section{Mechanical and thermal cycling}

The A groups were subjected to mechanical cycling in ER 3700 equipment (Erios, São Paulo, Brazil) for 120,000 mechanical cycles at a frequency of $4 \mathrm{~Hz}$, and at a loading of $88.4 \mathrm{~N} .{ }^{17}$ Force was applied at the center of the surface of the resin restoration, perpendicular to the dentin surface. Specimens were then submitted to 500 cycles in distilled water for $30 \mathrm{~s}$ in each temperature of $5 \pm 2$ and $55 \pm 2{ }^{\circ} \mathrm{C}$ using an ER 26000NG machine (Erios, São Paulo, Brazil). Artificial aging was performed to simulate changes that occur in the oral cavity during mastication. This can influence the adhesion between resin and substrate after temperature and mechanical injuries. ${ }^{18}$

\section{Preparing the beams and microtensile testing}

The specimens were mounted with the resin block perpendicular to the diamond cutting blade to obtain resin/dentin beams and with the adhesive interface area of approximately $1 \mathrm{~mm}^{2}$. The microtensile test was performed in a universal testing machine (DL-200MF, EMIC, São José dos Pinhais, Brazil), according to the standards described in ISO/TS11405:2015. Data were obtained in MPa.

Fractured beams wereinspected in a stereomicroscope (SteREO Discovery.V20, Carl Zeiss, Germany) to assess failure characteristics. The types of fracture were classified as cohesive in dentin, cohesive in resin, adhesive, or mixed. The percentage of each fracture type frequency was calculated.

\section{Statistics}

Cohesive and pretest failures were excluded from the analysis. The mean bond strength of beams per tooth was considered for statistical analysis, which was performed using a three-way analysis of variance (ANOVA) and Tukey's test at a 5\% significance level, using Statistica version 8 for Windows (StatSoft, Tulsa, USA). The chi-square test was used to compare the mode of failure (adhesive/mixed to other types of failure) within groups ( $\mathrm{p}<0.05)$.

\section{Results}

Adhesive failure was more prevalent in all groups. N_Er_A had a higher frequency (84.3\%), and N_S_Na showed higher frequency of pretest (9\%) and resin cohesive failures (1.5\%). The frequency of cohesive failure in dentin was highest for N_Er_Na (17.07\%) (Figure 1). E_S_Na presented the lowest frequency of adhesive/mixed failures compared to other groups $(\mathrm{p}<0.05)$, except when compared to N_Er_Na and E_Er_Na.

The mean and standard deviation values of the tested groups are presented in Table.

The 3-way ANOVA analysis revealed differences for ethanol $(\mathrm{p}<0.0001)$, adhesive application mode $(p=0.0002)$, and aging $(p<0.0001)$. It also showed differences in the interactions between ethanol and aging $(\mathrm{p}<0.0001)$, adhesive and aging ( $\mathrm{p}<0.0001)$, and among the three factors $(p=0.0003)$. 


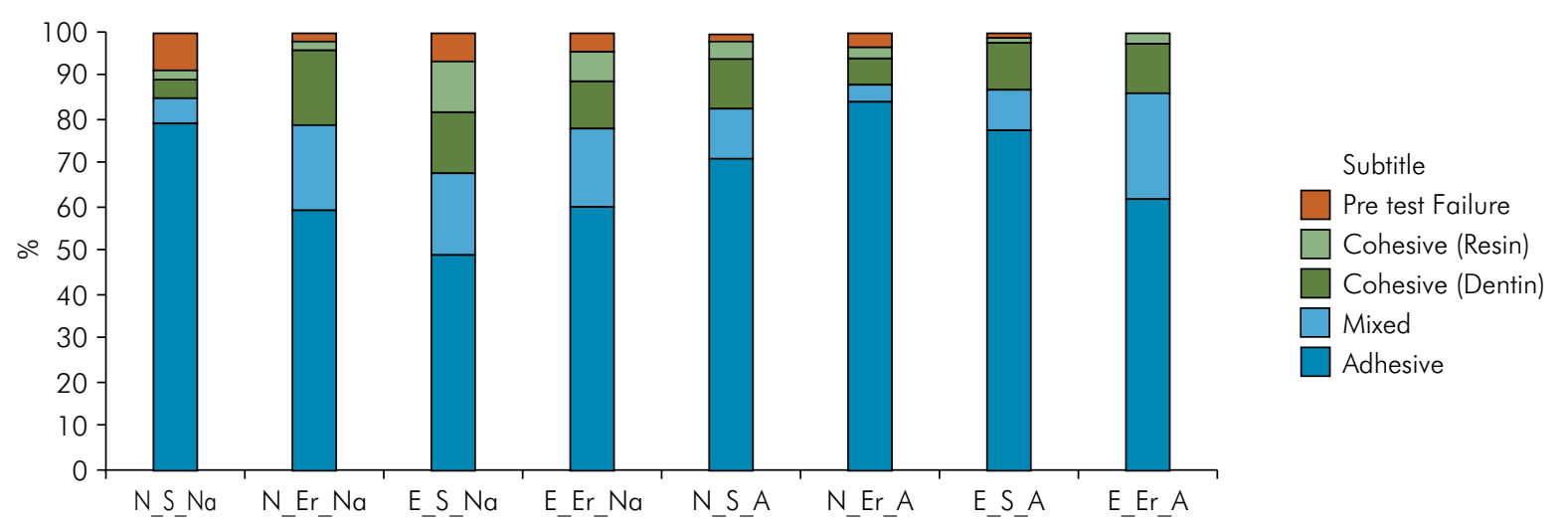

Figure 1. Percentage of fracture types wthin each group.

Table. Microtensile strength mean and standard deviation obtained in the different groups.

\begin{tabular}{lcccc}
\hline Application & Ethanol & Aging & Group code & Mean $(\mathrm{MPa}) \pm$ SD \\
\hline Etch-and-Rinse & No & Yes & N_Er_A & $9.83 \pm 0.53$ \\
Self-etch & No & Yes & N_S_A & $14.58 \pm 1.03$ \\
Self-etch & No & No & N_S_Na & $17.34 \pm 1.16$ \\
Etch-and-Rinse & No & No & N_Er_Na & $19.23 \pm 1.57$ \\
Etch-and-Rinse & Yes & Yes & E_Er_A & $20.88 \pm 1.59$ \\
Etch-and-Rinse & Yes & No & E_Er_Na & $21.20 \pm 2.53$ \\
Self-etch & Yes & No & E_S_Na & $22.19 \pm 2.12$ \\
Self-etch & Yes & Yes & E_S_A & $22.91 \pm 1.97$ \\
\hline
\end{tabular}

For the ethanol factor alone (Figure 2), the EWBT groups presented higher bond strength than the $\mathrm{N}$ ones, except for Er_Na groups. For the mode of adhesive application (Svs. Er), a self-etching technique resulted in higher bond strength values only for N_A groups (Figure 2). The other conditions were similar in their corresponding comparisons. The A groups presented higher bond strength values for the EWBT, regardless of the mode of adhesive application. For the aging factor (Figure 2), lower values were detected for the A groups when ethanol was not applied, regardless of the type of adhesive mode of application. The A groups behaved similarly to $\mathrm{Na}$ groups when the EWBT was employed, regardless of the mode of adhesive application.

\section{Discussion}

The alternative hypothesis, H1, was accepted in most comparisons among groups. The three null hypotheses $\left(\mathrm{H}_{\mathrm{o}} 2, \mathrm{H}_{\mathrm{o}} 3\right.$, and $\left.\mathrm{H}_{\mathrm{o}} 4\right)$ were rejected because all factors influenced the results $(p<0.05)$. The discussion section is divided according to the studied factors as follows:

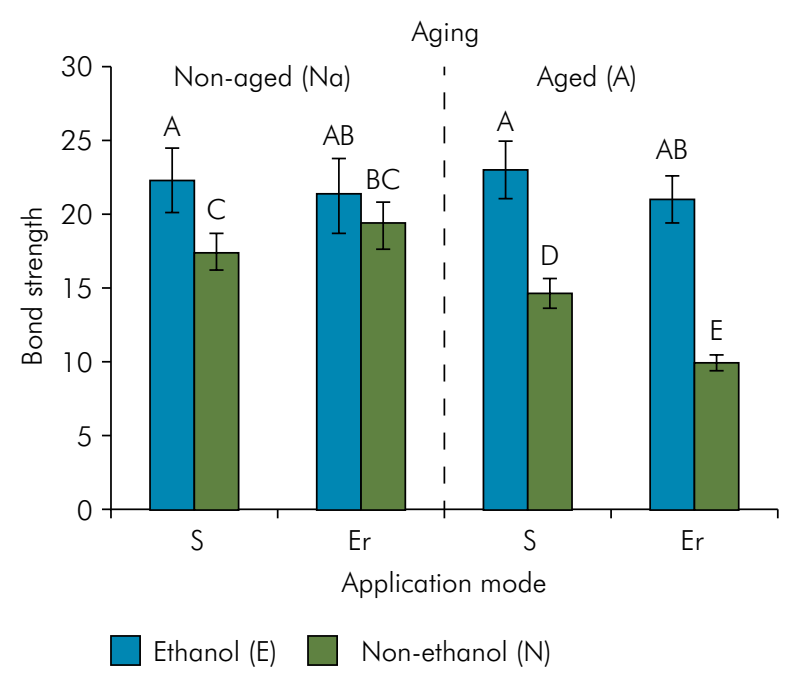

Figure 2. Graph presenting interaction among factors. 


\section{The influence of ethanol}

The first alternative hypothesis (H1), that the use of the ethanol technique positively influences the bond strength, was observed in most scenarios because the EWBT resulted in overall higher bond strength values, except for groups that received the etch-and-rinse within the non-aging protocol, that is, E_Er_Na was similar to N_Er_Na (Figure 2).

Ethanol is used to remove and replace free and loosely bound water around dentin tubule orifices and in the collagen microfibrils, so that the interfibrillar spaces are filled with ethanol. ${ }^{19,20}$ Contemporary adhesives are not able to completely remove water, leading to the dilution of monomers and water sorption of the adhesive layer during aging. ${ }^{20,21}$ The EWBT causes a decrease in the diameter of collagen fibrils due to an increase in intramolecular hydrogen bonding and a decrease in matrix volume. This consequently increases the size of interfibrillar spaces, which allows greater impregnation of the adhesive system and hydrophobic monomers. ${ }^{19}$ Also, there is less dentin matrix collapse compared to dentin moistened by water (WWB). That greater resin impregnation protects the collagen fibrils, increasing their rigidity, which contributes to the formation of a more effective hybrid layer. Additionally, a decrease in the amount of water in the bonding interface improves bond strength over time. ${ }^{22}$ Therefore, the EWBT favors the impregnation of methacrylates (BisGMA) in interfibrillar spaces and the formation of the hybrid layer. In addition, it improves mechanical properties because the greater the amount of hydrophobic infiltrated resin monomers, the greater the resin-dentin bonding strength. ${ }^{23}$ Those characteristics might explain the improved bond strength reported in groups using ethanol in the present study, especially after aging; for these groups, the mode of adhesive application did not influence the improved bond strength of ethanol groups.

Organic solvents, such as acetone and ethanol, within adhesive systems are preferred to water because they encourage the infiltration of resin monomers into collagen fibrils, resulting in better adhesive bond. ${ }^{4}$ According to Mair and Padipatvuthikul, ${ }^{24}$ organic solvents displace water molecules within the dentin matrix and, due to their high evaporation capacity, they facilitate the diffusion of monomers in demineralized dentin. The presence of residual solvent in the adhesive interface might result in disturbances in the polymerization reaction, which is deleterious to adhesion. The better the evaporation capacity, the lower the amount of residual solvent in the adhesive interface. ${ }^{25}$ In case the infiltration of monomers is incomplete, mainly due to high hydrophilicity, this scenario favors the formation of a porous hybrid layer, which is more prone to water absorption and solubility. Moreover, these features increase the toxicity potential by increasing the permeability of monomers and possibly compromising the longevity of restorations. ${ }^{24}$ The EWBT increases the absorption and degree of conversion of the resin monomers and produces a hydrophobic collagen matrix with improved sealing, even if a hydrophilic adhesive is used. In addition, the EWBT reduces the sorption of water and collagen hydrolysis, making the hybrid layer more stable over time. ${ }^{26}$ All those reported advantages might have aided the positive results obtained with a hydrophilic adhesive used in the present study.

On the other hand, some studies found no difference in bonding strength for a hydrophobic adhesive system when employed with the EWBT. Those results may be related to the difficulty of a proper ethanol application, the effective removal of water from the dentin substrate, which does not allow for satisfactory impregnation of hydrophobic monomers, and a possible adhesive dilution, which results in poor bonding of adhesives to dentin. ${ }^{26}$ The possibility of the infiltration of a hydrophilic resin monomer using the EWBT that focuses on higher bond strength and high resistance to mechanical stress was the target of the present study. Therefore, the application of a hydrophilic adhesive system might improve the interaction of the material with the dentin substrate, thus providing greater stability of the adhesive bonding interface. In this way, ethanol might have decreased the amount of water in the matrix and possibly allowed the infiltration of hydrophilic and hydrophobic resin monomers (Bis-GMA/TEGDMA) to create a more hydrophobic hybrid layer, which is supported by the present data. Furthermore, the interaction of a 10-MDP 
functional monomer, which can form strong ionic bonds with calcium hydroxyapatite in the substrate and thereby decrease the dissolution rate of Ca-salt formed, ${ }^{7}$ explains the higher microtensile strength observed in E_S_A.

The only exception is related to the lack of differences between E_Er_Na and N_Er_Na. The etch-and-rinse mode, when applied to dentin, is capable of dissolving apatite crystals and removing calcium, which, in part, is one component responsible for proper bonding when using universal adhesives presenting 10-MDP. ${ }^{27}$ However, such behavior after aging (E_Er_A > N_Er_A) was not detected, supporting the possible interaction of $10-\mathrm{MDP}$ with calcium that remained in the substrate. The difference in adhesion behavior should thus be related to the degradation of the bonding interface after aging, in which the $\mathrm{N}$ group presented lower bond strength. Although there are studies reporting possible inhibition of MDP by HEMA, ${ }^{28}$ the present results do not support such a statement.

\section{The influence of adhesive application mode}

The null hypothesis $\mathrm{H}_{0} 2$ was rejected because the mode of adhesive application significantly influenced bond strength (Figure 2). N_S_A showed higher values in relation to N_Er_A. This result is related to the characteristics provided by the adhesive system. When the adhesive is applied in self-etching mode to dentin, the incorporation of the smear layer and substrate minerals while forming the hybrid layer, as well as infiltration occurring simultaneously to demineralization, creates a thinner structure, which is more homogeneous and compacted by resin impregnation. Therefore, this is the preferred mode for bonding to dentin because it creates an efficient bond to the collagen network and substrate smear layer. ${ }^{29}$

However, the longevity of the bond of self-etch adhesive systems depends on the level of the acidic monomers, as they affect not only the bond strength but also its stability. Thus, a mild self-etching adhesive is currently recommended for adhesion to dentin. Furthermore, due to the absence of phosphoric acid application and an increase in superficial interaction with dentin, the degradation of the collagen fibrils may be reduced, directly affecting the stability of the bond over time. ${ }^{29}$

In the etch-and-rinse mode, a discrepancy between demineralization and infiltration of resin monomers in the adhesive interface leads to nano-infiltration and contributes to long-term instability, resulting in the degradation of unprotected collagen fibers in the hybrid layer. ${ }^{4,14}$ Moreover, the dissolution of apatite crystals from and among collagen fibrils, the activation of MMPs, and an increase of the dentin tubules lumen result in an increased amount of dentinal fluid in the interface, ${ }^{27,30}$ hindering the impregnation of collagen fibers by adhesive monomers. ${ }^{31}$ This leaves collagen fibrils unprotected and more exposed to hydrolysis, enzymatic attacks, and functional and thermal stressors (Figure 2). ${ }^{13}$

A universal adhesive system in self-etching mode increases the adhesive effectiveness and longevity. This suggests that the acidic primer in the adhesive composition is sufficient to promote demineralization. In addition, it allows the infiltration of resinous monomers and 10-MDP and decreases the possibility of nano-infiltration. ${ }^{2}$ Moreover, the incorporation of undissolved calcium phosphates, which are unstable in aqueous media, weakens interfacial integrity, ${ }^{27}$ but the EWBT allows the formation of an environment with less water and thus favors bonding between the substrate and the universal adhesive. ${ }^{2}$

The gently applicied ethanol may interact with the smear layer by modifying the organic matrix, leaving crystals susceptible to bonding with the adhesive system, and possibly assisting the interdiffusion of adhesive monomers within collagen fibrils. This fact might favor self-etch adhesives because they interact more superficially with the dentin substrate and also favor the bonding of 10-MDP to calcium ions.

The present results are in accordance with these characteristics, as the self-etching application method presented results similar to the total-acid etching technique, except for N_S_A, which was greater than N_Er_A $(14.58>9.83 \mathrm{MPa})$. Therefore, tissue changes that are unfavorable to bonding occur after total-acid etching. In addition, based on the results of this study, combined with a hydrophilic self-etching adhesive system and dentin pretreatment with $100 \%$ ethanol, the 
EWBT might demonstrate an improvement in the stability of the adhesive interface and therefore the clinical longevity of the restoration. This avoids reoccurrence of caries, marginal gaps, nanoinfiltration, postoperative sensitivity, and premature adhesive failures in restorative procedures. Further studies for understanding the role of ethanol on the dentin smear layer are necessary to completely understand the behavior of such combinations regarding the results of the present study.

\section{The effect of thermomechanical cycling}

The null hypothesis $\mathrm{H}_{0} 3$ was rejected because aging significantly influenced bonding strength; the A groups showed lower bonding values compared to the Na groups. ${ }^{32}$ This observation was not detected in the ethanol-treated specimens. Thus, pretreatment with $100 \%$ ethanol might be performed to increase the longevity of the adhesive bond to the dentin substrate (Figure 2).

Because the Single Bond Universal adhesive system also presents ethanol as a solvent, the EWBT may have facilitated the impregnation of resin monomers, resulting in a stable bonding, ${ }^{33}$ even after artificial aging. This is supports by data from the EWBT groups, which presented no changes in bond strength after aging. The incomplete replacement of water in the bonding interface leads to lower impregnation of monomers and maintenance of a wet collagen matrix, which adversely affects bonding strength when subjected to aging. As a result, this facilitates the hydrolysis of the hybrid layer and thus decreases the longevity of restoration.

Another feature that contributes to bond longevity between a universal adhesive system and dentin is the maintenance of hydroxyapatite (HAp) around the collagen fibrils even after aging. This protects them from hydrolysis and consequent degradation of the adhesive interface. ${ }^{2,30}$ Regardless of the mode of application of a universal adhesive system, the results of the E_A groups were similar to the E_Na groups. Thus, these results suggest that ethanol has the ability to maintain the characteristics of the adhesive bond. This result might be directly linked to the characteristics of ethanol-saturated dentin, which has collagen fibrils of smaller diameter and increased interfibrillar spaces, favoring the impregnation of the resin monomers and hence present increased bonding strength. ${ }^{22,33}$ Hydrophobic monomers in the collagen matrix decrease water sorption and hydrolytic cleaving catalyzed by collagen enzymes. ${ }^{34}$

Due to the composition of self-etching adhesives (acidic resinous monomers, hydrophilic monomers of low molecular weight, and functional monomers, such as 10-MDP), the presence of water is important for ionizing the acidic monomers and allowing simultaneous demineralization and infiltration within substrates. ${ }^{25}$ The interaction of 10-MDP with calcium hydroxyapatite in the substrate maintains the bonding durability of the adhesive interface in the long term. ${ }^{7}$ Concerns regarding the influence of ethanol-dehydrated dentin on the bonding ability of universal adhesives might be reported mainly due to the presence of a polyalkenoic acid copolymer. ${ }^{5}$ The improved bond strength detected in the $\mathrm{E}$ and A groups in the present study and the clinical finding ${ }^{35}$ confirming proper bonding behavior in dehydrated dentin support the assumption that there should be no bonding influence of dehydrated dentin while using universal adhesives. Moreover, the main component for polyalkenoic acid copolymer ${ }^{5}$ adhesion is hydroxyapatite, which is a secondary parameter for dentin bonding. This also supports our previous supposition.

Questions on pulp reaction following the application of $100 \%$ ethanol to dentin might be raised. However, no difference in pulp reaction have been reported while using such a protocol in previously conditioned deep cavities $(0.5 \mathrm{~mm})$ in comparison to calcium hydroxide application. ${ }^{33}$ The disruption of the superficial odontoblastic layer with no compromise to subsequent layers was detected in both water- and ethanol-bonding protocols in the reported study. This fact was observed after $48 \mathrm{~h}$, and the authors discuss a possible complete recovery from this mild injury after the bonding therapies. ${ }^{33}$

The in vitro character of this study does not allow extrapolation to an in vivo situation; in vivo results should be investigated. Furthermore, future studies should evaluate the impregnation of the adhesive system on dentin after the EWBT. 


\section{Conclusion}

Based on the results of the present study, in which the EWBT showed higher mean microtensile values especially after aging, the authors conclude that the use of universal adhesives with the ethanol-wet bonding procedure is approved for more studies with possible future clinical indications.

\section{References}

1. Terrer E, Raskin A, Koubi S, Dionne A, Weisrock G, Sarraquigne $C$ et al. A new concept in restorative dentistry: LIFEDT-light-induced fluorescence evaluator for diagnosis and treatment: part 2 - treatment of dentinal caries. J Contemp Dent Pract. 2010 Jan;11(1):E095-102.

2. Perdigão J, Kose C, Mena-Serrano A, De Paula E, Tay L, Reis $A$ et al. A new universal simplified adhesive: 18-month clinical evaluation. Oper Dent. 2014 Mar-Apr;39(2):113-27. https://doi.org/10.2341/13-045-C

3. Miyazaki M, Tsujimoto A, Tsubota K, Takamizawa T, Kurokawa H, Platt JA. Important compositional characteristics in the clinical use of adhesive systems. J Oral Sci. 2014 Mar;56(1):1-9. https://doi.org/10.2334/josnusd.56.1

4. Ahn J, Jung KH, Son SA, Hur B, Kwon YH, Park JK. Effect of additional etching and ethanol-wet bonding on the dentin bond strength of one-step self-etch adhesives. Restor Dent Endod. 2015 Feb;40(1):68-74. https://doi.org/10.5395/rde.2015.40.1.68

5. Suda S, Tsujimoto A, Barkmeier WW, Nojiri K, Nagura $Y$, Takamizawa $T$ et al. Comparison of enamel bond fatigue durability between universal adhesives and two-step self-etch adhesives: effect of phosphoric acid pre-etching. Dent Mater J. 2018 Mar;37(2):244-55. https://doi.org/10.4012/dmi.2017-059

6. Rosa WL, Piva E, Silva AF. Bond strength of universal adhesives: a systematic review and meta-analysis. J Dent. 2015 Jul;43(7):765-76. https://doi.org/10.1016/j.jdent.2015.04.003

7. Yokota Y, Fujita KN, Uchida R, Aida E, Aoki NT, Aida M et al. Quantitative evaluation of MDP-Ca salt and DCPD after application of an MDP-based one-step self-etching adhesive on enamel and dentin. J Adhes Dent. 2016;18(3):205-13. https://doi.org/10.3290/j.jad.a36133

8. Nishitani Y, Yoshiyama M, Donnelly AM, Agee KA, Sword J, Tay FR et al. Effects of resin hydrophilicity on dentin bond strength. J Dent Res. 2006 Nov;85(11):1016-21. https://doi.org/10.1177/154405910608501108

9. Pashley DH, Tay FR, Carvalho RM, Rueggeberg FA, Agee KA, Carrilho $M$ et al. From dry bonding to water-wet bonding to ethanol-wet bonding: a review of the interactions between dentin matrix and solvated resins using a macromodel of the hybrid layer. Am J Dent. 2007 Feb;20(1):7-20.
10. Breschi L, Mazzoni A, Ruggeri A, Cadenaro M, Di Lenarda $R$, Dorigo ES. Dental adhesion review: aging and stability of the bonded interface. Dent Mater. 2008 Jan;24(1):90-101. https://doi.org/10.1016/j.dental.2007.02.009

11. Sadek FT, Castellan CS, Braga RR, Mai S, Tiäderhane $\mathrm{L}$, Pashley DH et al. One-year stability of resin-dentin bonds created with a hydrophobic ethanol-wet bonding technique. Dent Mater. 2010 Apr;26(4):380-6. https://doi.org/10.1016/i.dental.2009.12.009

12. Sauro S, Toledano M, Aguilera FS, Mannocci F, Pashley DH, Tay FR et al. Resin-dentin bonds to EDTA-treated vs. acid-etched dentin using ethanol wet-bonding. Part II: effects of mechanical cycling load on microtensile bond strengths. Dent Mater. 2011 Jun;27(6):563-72. https://doi.org/10.1016/i.dental.2011.02.010

13. Nagpal R, Manuja N, Pandit IK. Effect of ethanol wet bonding technique on the durability of resin- dentin bond with contemporary adhesive systems. J Clin Pediatr Dent. 2015;39(2):133-42. https://doi.org/10.17796/jcpd.39.2.p14u4×3q14272452

14. Pashley DH, Tay FR, Breschi L, Tiäderhane L, Carvalho RM, Carrilho $M$ et al. State of the art etch-and-rinse adhesives. Dent Mater. 2011 Jan;27(1):1-16. https://doi.org/10.1016/i.dental.2010.10.016

15. Ting S, Chowdhury AA, Pan F, Fu J, Sun J, Kakuda S et al. Effect of remaining dentin thickness on microtensile bond strength of current adhesive systems. Dent Mater. 2015 Apr;34(2):181-8. https://doi.org/10.4012/dmj.2014-130

16. Singh V, Misra A, Marangos $O$, Park J, Ye Q, Kieweg SL et al. Viscoelastic and fatigue properties of model methacrylatebased dentin adhesives. J Biomed Mater Res B Appl Biomater. 2010 Nov;95(2):283-90. https://doi.org/10.1002/jbm.b.31712

17. Salz U, Bock T. Testing adhesion of direct restoratives to dental hard tissue: a review. J Adhes Dent. 2010 Oct;12(5):343-71.

18. Bedran-de-Castro AK, Cardoso PE, Ambrosano GM, Pimenta LA. Thermal and mechanical load cycling on microleakage and shear bond strength to dentin. Oper Dent. 2004 Jan-Feb;29(1):42-8.

19. Hosaka K, Nishitani Y, Tagami J, Yoshiyama M, Brackett WW, Agee KA et al. Durability of resin-dentin bonds to water- vs. ethanol-saturated dentin. J Dent Res. 2009 Feb;88(2):146-51. https://doi.org/10.1177/0022034508328910 
20. Osorio E, Toledano M, Aguilera FS, Tay FR, Osorio

R. Ethanol wet-bonding technique sensitivity assessed by AFM. J Dent Res. 2010 Nov;89(11):1264-9. https://doi.org/10.1177/0022034510376403

21. Mortazavi V, Samimi P, Rafizadeh M, Kazemi S. A randomized clinical trial evaluating the success rate of ethanol wet bonding technique and two adhesives. Dent Res J (Isfahan). 2012 Sep;9(5):588-94. https://doi.org/10.4103/1735-3327.104878

22. Tay FR, Pashley DH, Kapur RR, Carrilho MR, Hur YB, Garrett $\mathrm{LV}$ et al. Bonding BisGMA to dentin-a proof of concept for hydrophobic dentin bonding. J Dent Res. 2007 Nov;86(11):10349. https://doi.org/10.1177/154405910708601103

23. Kim J, Gu L, Breschi L, Tjäderhane L, Choi KK, Pashley DH et al. Implication of ethanol wet-bonding in hybrid layer remineralization. J Dent Res. 2010 Jun;89(6):575-80. https://doi.org/10.1177/0022034510363380

24. Mair L, Padipatvuthikul P. Variables related to materials and preparing for bond strength testing irrespective of the test protocol. Dent Mater. 2010 Feb;26(2):e17-23. https://doi.org/10.1016/i.dental.2009.11.154

25. Salvio LA, Hipólito VD, Martins AL, Goes MF. Hybridization quality and bond strength of adhesive systems according to interaction with dentin. Eur J Dent. 2013 Jul;7(3):315-26. https://doi.org/10.4103/1305-7456.115416

26. Tiäderhane L, Nascimento FD, Breschi L, Mazzoni A, Tersariol IL, Geraldeli S et al. Strategies to prevent hydrolytic degradation of the hybrid layer: review. Dent Mater. 2013 Oct;29(10):999-1011. https://doi.org/10.1016/j.dental.2013.07.016

27. Van Meerbeek B, Yoshihara K, Yoshida Y, Mine A, De Munck J, Van Landuyt KL. State of the art of selfetch adhesives. Dent Mater. 2011 Jan;27(1):17-28. https://doi.org/10.1016/i.dental.2010.10.023
28. Tian F, Zhou L, Zhang Z, Niu L, Zhang L, Chen C et al. Paucity of Nanolayering in Resin-Dentin Interfaces of MDP-based Adhesives. J Dent Res. 2016 Apr;95(4):380-7. https://doi.org/10.1177/0022034515623741

29. Rosa WL, Piva E, Silva AF. Bond strength of universal adhesives: A systematic review and meta-analysis. J Dent. 2015 Jul;43(7):765-76. https://doi.org/10.1016/i.jdent.2015.04.003 duplicata da 6

30. Mine A, De Munck J, Cardoso MV, Van Landuyt KL, Poitevin A, Van Ende A et al. Dentin-smear remains at self-etch adhesive interface. Dent Mater. 2014 Oct;30(10):1147-53. https://doi.org/10.1016/j.dental.2014.07.006

31. Yesilyurt C, Ayar MK, Yildirim T, Akdag MS. Effect of simplified ethanol-wet bonding on dentin bonding durability of etchand-rinse adhesives. Dent Mater J. 2015;34(4):441-8. https://doi.org/10.4012/dmi.2014-335

32. Carvalho RM, Mendonça JS, Santiago SL, Silveira RR, Garcia FC, Tay FR et al. Effects of HEMA/solvent combinations on bond strength to dentin. J Dent Res. 2003 Aug;82(8):597-601. https://doi.org/10.1177/154405910308200805

33. Scheffel DL, Sacono NT, Ribeiro AP, Soares DG, Basso FG, Pashley D et al. Immediate human pulp response to ethanol-wet bonding technique. J Dent. 2015 May;43(5):53745. https://doi.org/10.1016/i.jdent.2015.02.014

34. Liu Y, Tiäderhane L, Breschi L, Mazzoni A, Li N, Mao $J$ et al. Limitations in bonding to dentin and experimental strategies to prevent bond degradation. J Dent Res. 2011 Aug;90(8):953-68. https://doi.org/10.1177/0022034510391799

35. Loguercio AD, Paula EA, Hass V, Luque-Martinez I, Reis A, Perdigão J. A new universal simplified adhesive: 36-month randomized double-blind clinical trial. J Dent. 2015 Sep;43(9):1083-92. https://doi.org/10.1016/i.jdent.2015.07.005 